\title{
Verification of RSRM Nozzle Thermal Models With ETM-3 Aft Exit Cone In-depth Temperature Measurements
}

\author{
Joel F. Maw ${ }^{1}$, Robbie C. Lui ${ }^{2}$, and Peter D. Totman ${ }^{3}$ \\ ATK Thiokol, Brigham City, UT 84302
}

\begin{abstract}
One of the goals of the Engineering Test Motor (ETM-3) static test was to verify analytical models through the use of instrumentation that provide real-time transient temperature response of ablating phenolic liners. Accurate measurement of in-depth temperature is critical for validating the analytical models and assessing design safety margins for nozzle insulation materials. Recent developments of in-depth thermocouple plugs have been made to more accurately measure temperature response of nozzle liners. Thermocouple plugs were installed at two axial stations (four plugs circumferentially at each station) near the end of the ETM-3 nozzle aft exit cone to gather temperature histories during and after motor operation. The thermocouple plugs were placed at depths that bounded the reusable solid rocket motor nominal measured char depth in order to portray the carbon phenolic temperature response during the charring process. The data were used to verify the analytical models during motor operation and to better define char penetration during heat soak after motor burn out.
\end{abstract}

\section{Introduction}

$\mathrm{T}$ HE ETM-3 motor was designed with five RSRM segments in order to enhance motor performance and internal environments. The test was in support of both the RSRM and the Five Segment Booster (FSB) programs. The test was designated as a margin test for RSRM, while utilizing many of the FSB design features. One of the major objectives of the test was to assess the enhanced nozzle thermal environments. The ETM-3 nozzle was designed to maximize throat diameter while maintaining acceptable margins and historical geometric compatibility. The throat inlet/throat carbon-cloth phenolic (CCP) rings were recontoured to accommodate the larger throat diameter and optimize motor performance. An extended aft exit cone (AEC) was also employed to maximize thrust. Aside from the recontoured throat inlet and throat rings, and the extended AEC, the as-built flame side contour is identical to the current RSRM flight design. The ETM-3 nozzle configuration is depicted in Fig. 1.

The designation of the ETM-3 motor as a margin test enabled ATK Thiokol Engineering the opportunity to incorporate many engineering assessments not normally included on a typical static test motor. One significant evaluation from the test was made with the application of in-depth thermocouple (TC) plugs in the AEC of the nozzle. The TC plugs were designed to record temperature histories during and after motor operation. In-depth TC plug technology has been successfully applied on various motor nozzles used in other programs including ModifiedNASA Advanced Solid Rocket Motor (MNASA-ASRM), CASTOR $120^{\circledR}$ strap-on boosters, Solid Propulsion Integrity Program (SPIP), and Low-Cost Commercial Liquid Rocket Motor RS-68.

This paper discusses the development of the TC plug design, the verification methods used to ensure the optimal design, and the placement for use in the ETM-3 AEC. The correlation of the temperature data gathered by the TC plugs to the analytical model is also addressed.

\footnotetext{
${ }^{1}$ Sr. Principal Scientist, Heat Transfer, PO Box 707, MS 252

${ }^{2}$ Design Engineer, Nozzle Design, PO Box 707, MS LE1

${ }^{3}$ Instrumentation Engineer, Transducer Development, PO Box 707, MS J61E
}

Copyright $@ 2004$ by ATK Thiokol, an Alliant Techsystem affiliate.

Published by the American Institute of Aeronautics and Astronautics, Inc., with permission. 


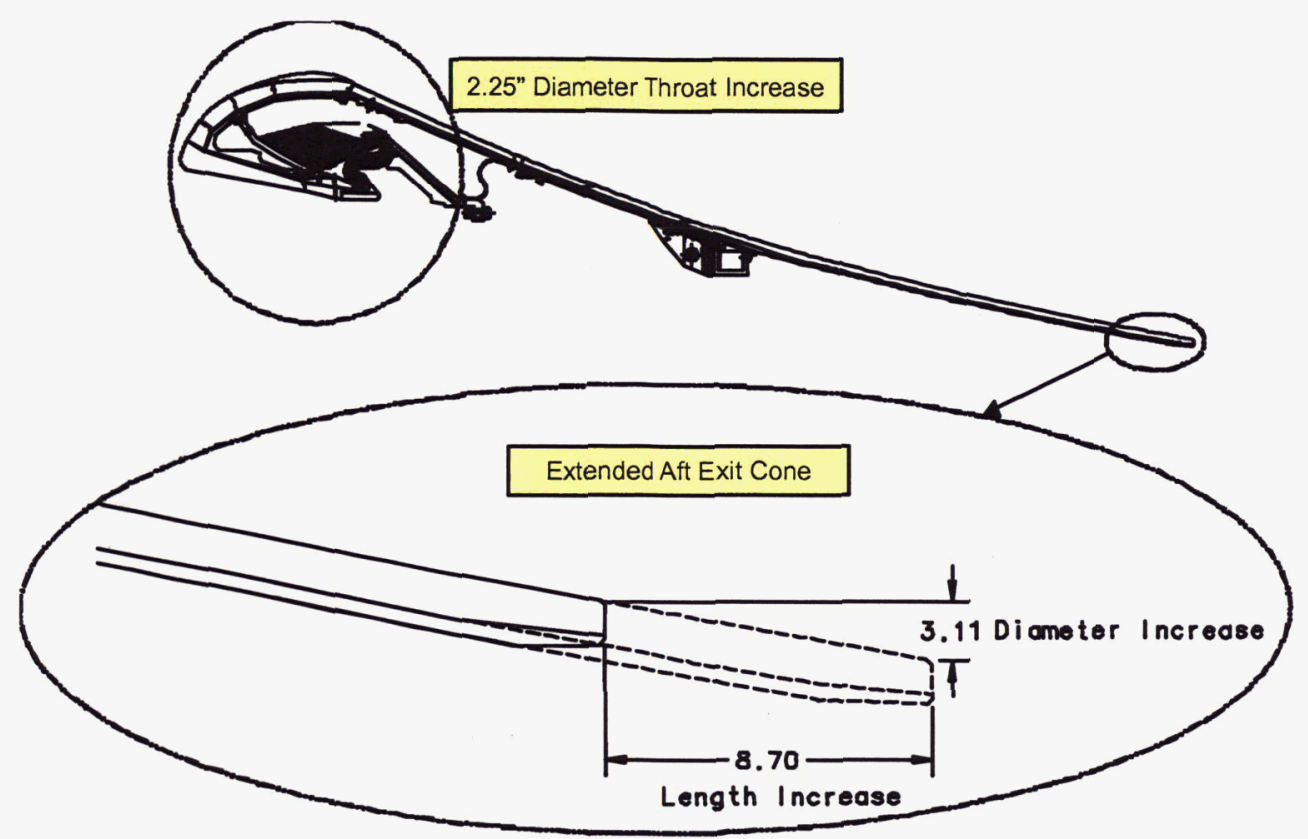

Figure 1: ETM-3 Nozzle Configuration

\section{Discussion}

In-depth TC plug technology has been utilized previously on nozzles in other ATK Thiokol programs including MNASA-ASRM, CASTOR $120^{\circledR}$, SPIP, and RS-68. That technology was incorporated and further improved during the development of the TC plugs that were installed in the ETM-3 AEC. Testing was completed at the Laser Hardened Material Evaluation Laboratory (LHMEL) facility to assist in down-selecting the final ETM-3 TC plug configuration. After the ETM-3 TC plug configuration was selected, TC plugs were installed on a Solid Rocket Test Motor (SRTM) 24-in. nozzle as a verification test prior to ETM-3. Following the successful application on the SRTM nozzle, the TC plugs were installed on the ETM-3 nozzle.

\section{A. Thermocouple Development and Evaluation}

The Transducer Development organization at ATK Thiokol was tasked with developing a TC plug design that would best replicate the "ideal case," which would be embedded or cured-in-place TCs. The three initial TC plug configurations that were conceived are shown in Fig. 2. Five CCP block samples were sent to the LHMEL test facility to serve as preliminary test runs prior to the down-selection of the TC plug configurations. The primary purpose of the LHMEL "hot block" testing was to down-select a TC design for the ETM-3 nozzle exit cone. Hence, the first set of tests consisted of firing the three TC plug configurations considered for the ETM-3 design. Instrumented CCP blocks ( $3.5 \times 3.5 \times 1$-in. thick, 10-deg. ply angle) with one TC plug in the center at approximately a 0.2 -in. depth were exposed to $300 \mathrm{~W} / \mathrm{cm} 2$-s for 30 seconds. The TCs were placed at a depth such that they would reach $1000^{\circ} \mathrm{F}$ (CCP char depth) or greater by the end of the test. The data from each of the plug configurations were compared to data from the "ideal case," which consisted of blocks with the cured-in-place TCs. Down-selection of plugs was based on data repeatability and comparison with the control blocks. The LHMEL test matrix is in Table 1.

The comparison showed little difference between the data for each of the three configurations. Each one of the configurations tracked the control cases fairly well. However, during the early stages of the testing, a decision was made to prioritize the tests because of LHMEL facility schedule constraints. Based on the data from the first two tests of each configuration, the ELS-873-07 configuration was eliminated since the data from that configuration appeared to respond slightly slower than the other two configurations. 


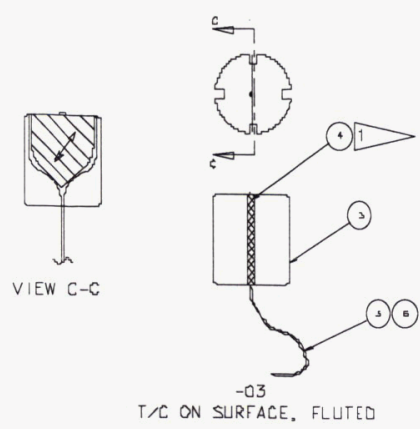

EI.S-873-(04

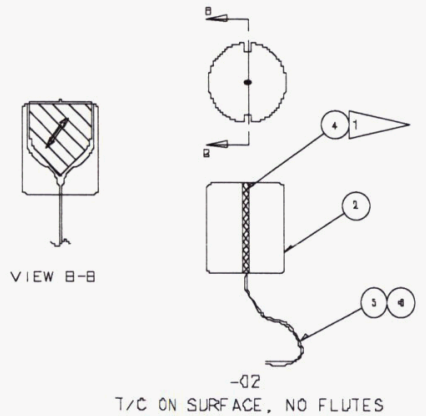

FI SS-873-06

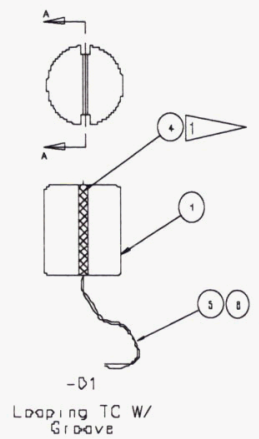

FI S-872-n7

Figure 2: Initial TC Plug Configurations

Table 1: LHMEL Test Matrix

\begin{tabular}{|c|c|c|c|c|c|l|}
\hline Test & ELS-873 & $\begin{array}{c}\text { No. of } \\
\text { Blocks }\end{array}$ & $\begin{array}{c}\text { Ply Angle } \\
\text { (deg.) }\end{array}$ & $\begin{array}{c}\text { Heat Flux } \\
\text { (W/cm } \mathbf{~}^{\mathbf{S}} \text { ) }\end{array}$ & $\begin{array}{c}\text { Time } \\
(\mathbf{s})\end{array}$ & \multicolumn{1}{c|}{ Descriptions } \\
\hline 1 & -01 & 5 & 90 & 600 & 150 & Evaluate pocketing effect \\
\hline 2 & -02 & 5 & 55 & 600 & 150 & Simulate nozzle Joint 4 environment \\
\hline 3 & -03 & 5 & 21 & 300 & 150 & Simulate nozzle Joint 1 environment \\
\hline 4 & -04 & 5 & 10 & 300 & 30 & TC plug down selection \\
\hline 5 & -06 & 5 & 10 & 300 & 30 & TC plug down selection \\
\hline 6 & -07 & 5 & 10 & 300 & 30 & TC plug down selection \\
\hline 7 & -05 & 5 & 10 & 300 & 30 & Ideal case with cured-in-place TC wire \\
\hline
\end{tabular}

Figures 3 through 5 present the results of the first set of testing. Figure 3 shows the data from the ELS-873-04 TC plugs that included four total slots - two slots for the TC wires and two additional slots or flutes for adhesive relief during installation. Figure 4 presents the data from the ELS-873-06 TC plugs that included only two slots for the TC wires. Figure 5 shows the data from the ELS-873-07 TC plugs that had two slots for the TC wires with a springloaded TC. Each one of the charts also includes the resulting data from the control case tests, which had the curedin-place TCs.

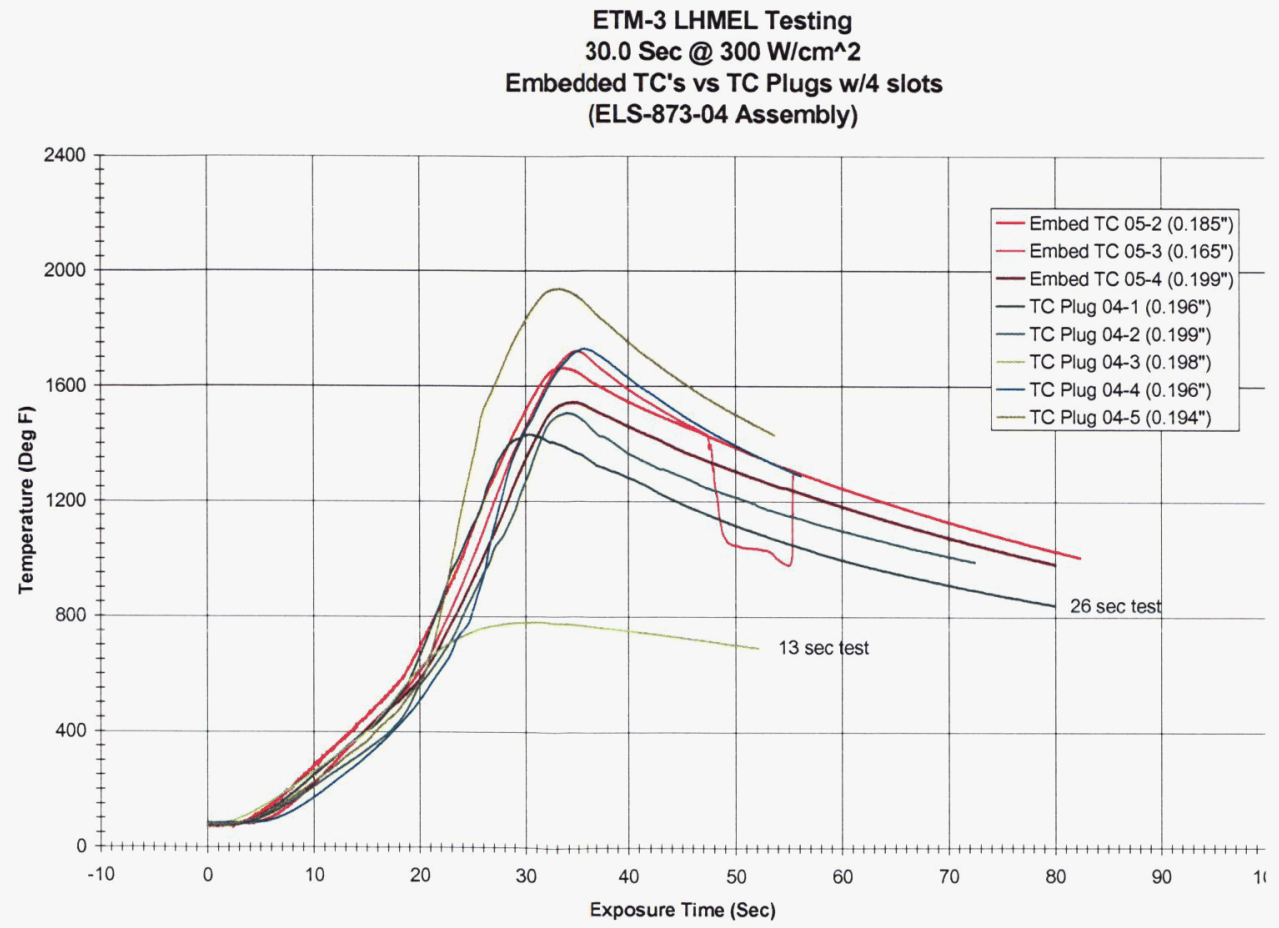

Figure 3: ELS-873-04 TC Plug LHMEL Test Results 


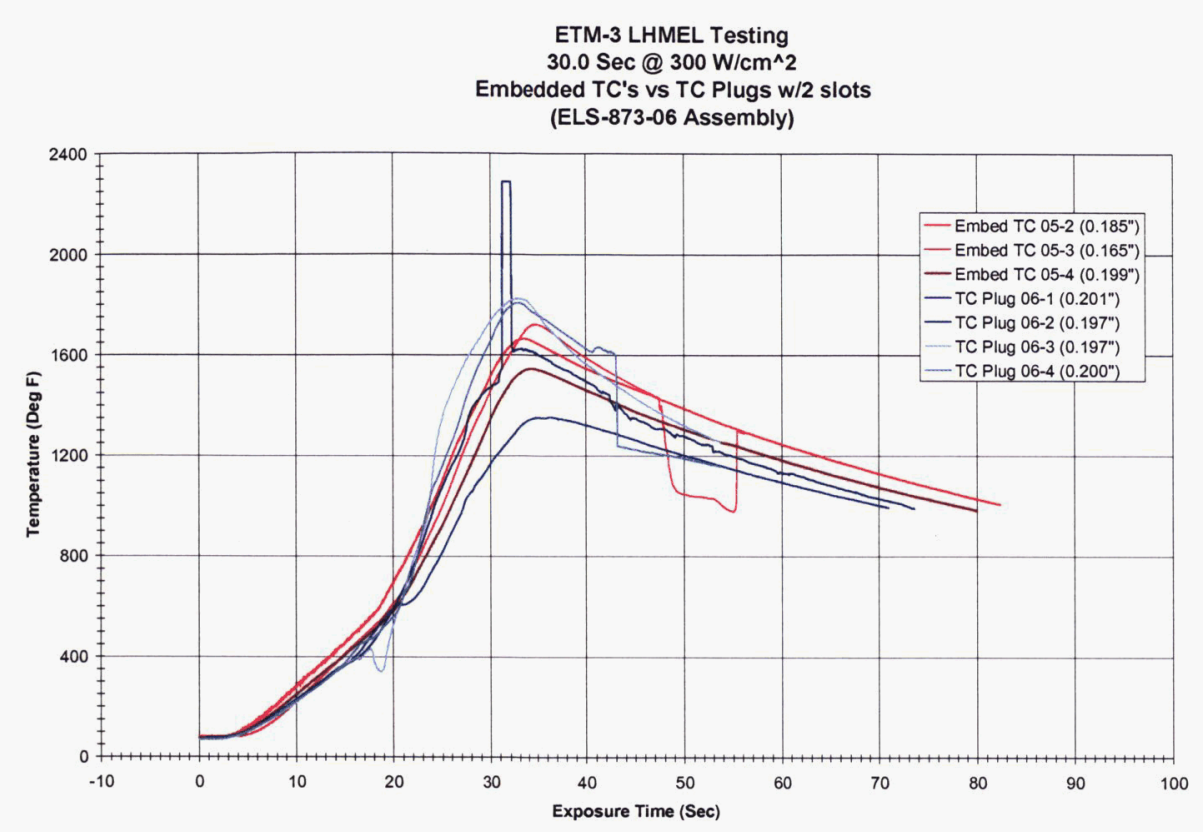

Figure 4: ELS-873-06 TC Plug LHMEL Test Results

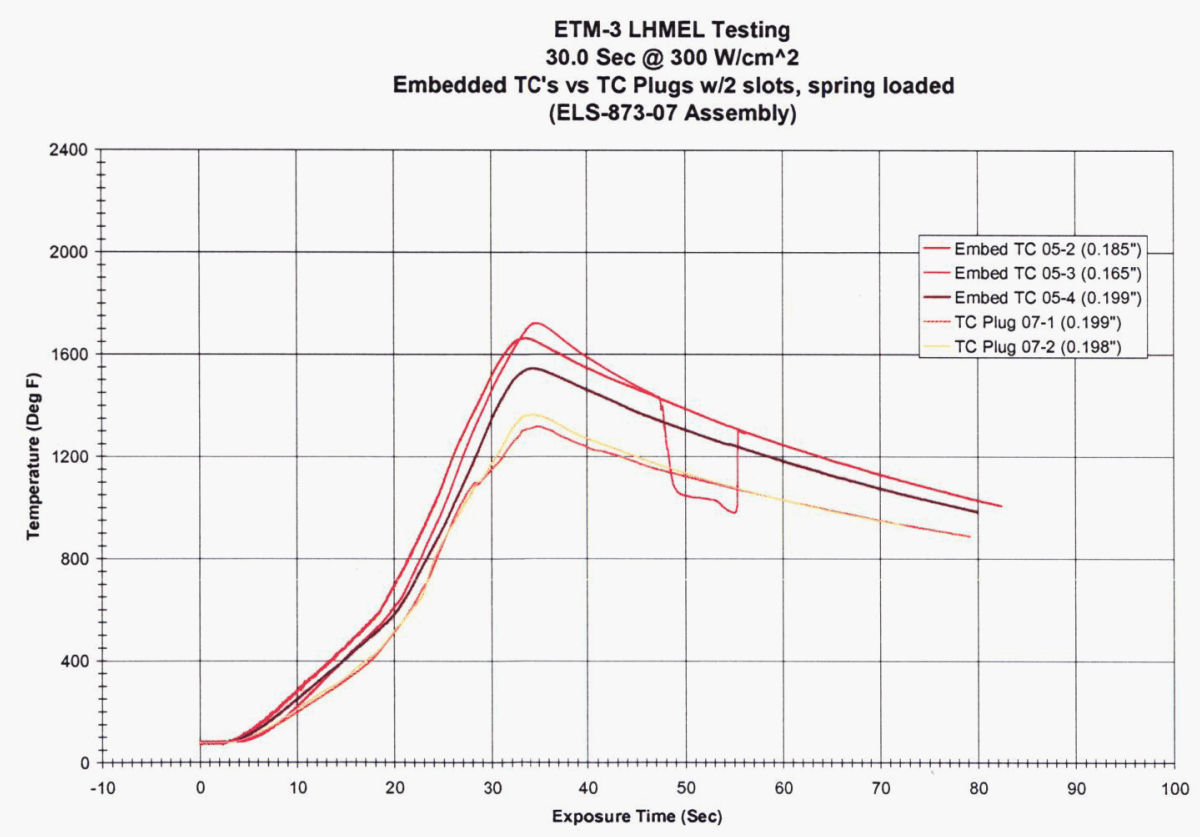

Figure 5: ELS-873-07 TC Plug LHMEL Test Results

The results of the testing showed that either configuration (ELS-873-04 or ELS-873-06) would be acceptable for application on ETM-3. The resulting TC data from both of the configurations tracked the control cases very well and were quite consistent from test to test. The ELS-873-04 configuration was chosen because of the adhesive relief design feature. The flutes were actually designed in as a channel that would allow trapped air and adhesive to extrude out during installation. That was the original intent, but the design changed slightly during installation. Small tubes were placed inside the flutes to allow the air ahead of the adhesive dam to escape through the tubes. This prevented a plunger effect that would leave air bubbles in the adhesive. This allows additional volume for the adhesive to fill during installation of the plug. 
A second set of tests was conducted to assess eroding/char performance with the presence of the "intrusive" hole and plug. These consisted of three configurations that were tested to simulate three different areas of the nozzle that were proposed to house the TC plugs. The TCs were again placed at a depth to experience temperatures at or near $1000^{\circ} \mathrm{F}$ at the end of the test. The ELS-873-01 assembly had a 90-degree ply angle and was exposed to $600 \mathrm{~W} / \mathrm{cm} 2-\mathrm{s}$ for 100 seconds. This represents the environment that is experienced at Joint 4 (throat ring-to-forward exit cone (FEC)) of the RSRM nozzle with a worst-case 90-degree ply angle. The TCs were placed at a depth of $\sim 1.0$ inch. The ELS-873-02 assembly had a 55-degree ply angle and was exposed to $600 \mathrm{~W} / \mathrm{cm} 2$-s for 100 to 133 seconds. This again represents the environment that is seen at Joint 4 of the RSRM nozzle with a ply angle representative of the FEC. The TCs were again placed at a depth of $~ 1.0$ inch. The ELS-873-03 assembly had a 21-degree ply angle and was exposed to $300 \mathrm{~W} / \mathrm{cm} 2$-s for 150 seconds. This represents the environment that is seen at Joint 1 (FEC-to-AEC) of the RSRM nozzle with a ply angle representative of the AEC. These TCs were placed at a depth of $\sim 0.7$ inch.

Figures 6 through 8 show the TC results from the second set of testing. Again, the TC temperature histories are fairly consistent from test to test. Figure 9 is a cross-sectional view of each of the TC plug configurations. As can be seen from the figure, no pocketing, ply lifting, or spalling was observed in any of the sectioned parts. This demonstrated that the presence of TC plugs in the nozzle would have no adverse effect on the ablative performance of the CCP liners.

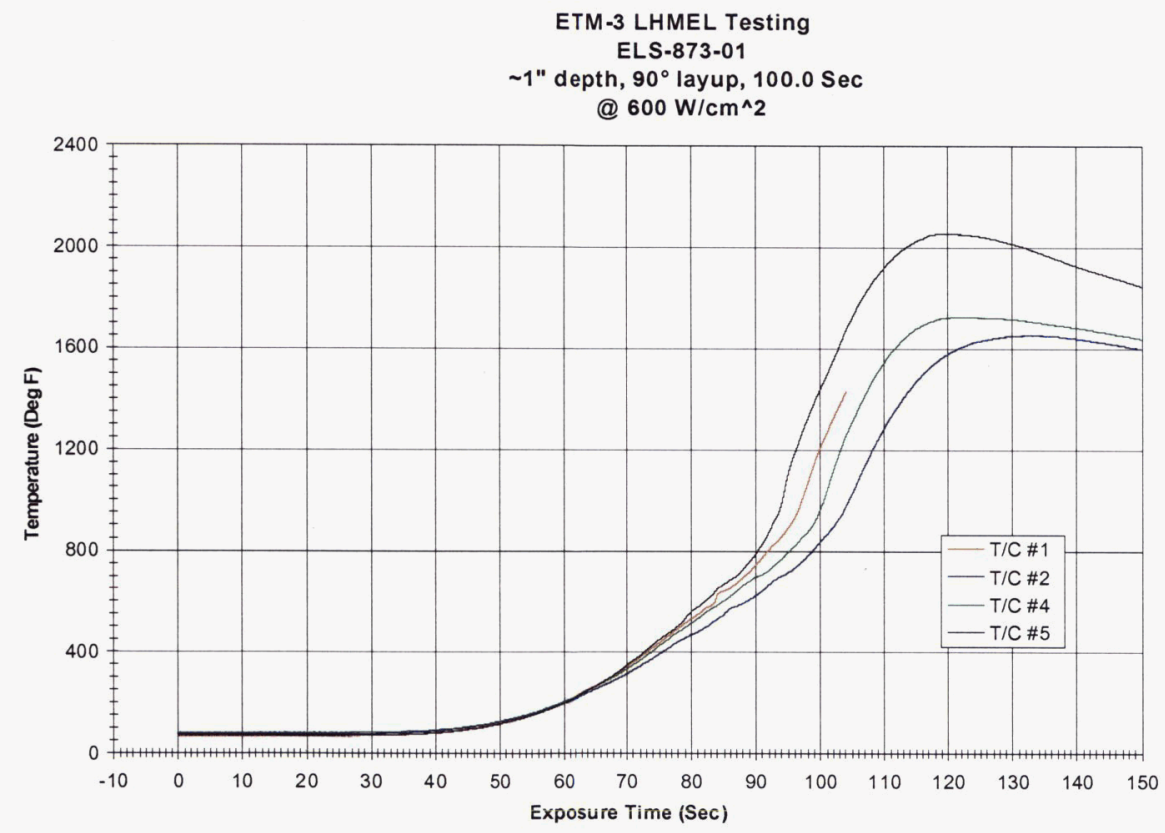

Figure 6: ELS-873-01 TC Plug LHMEL Test Results 


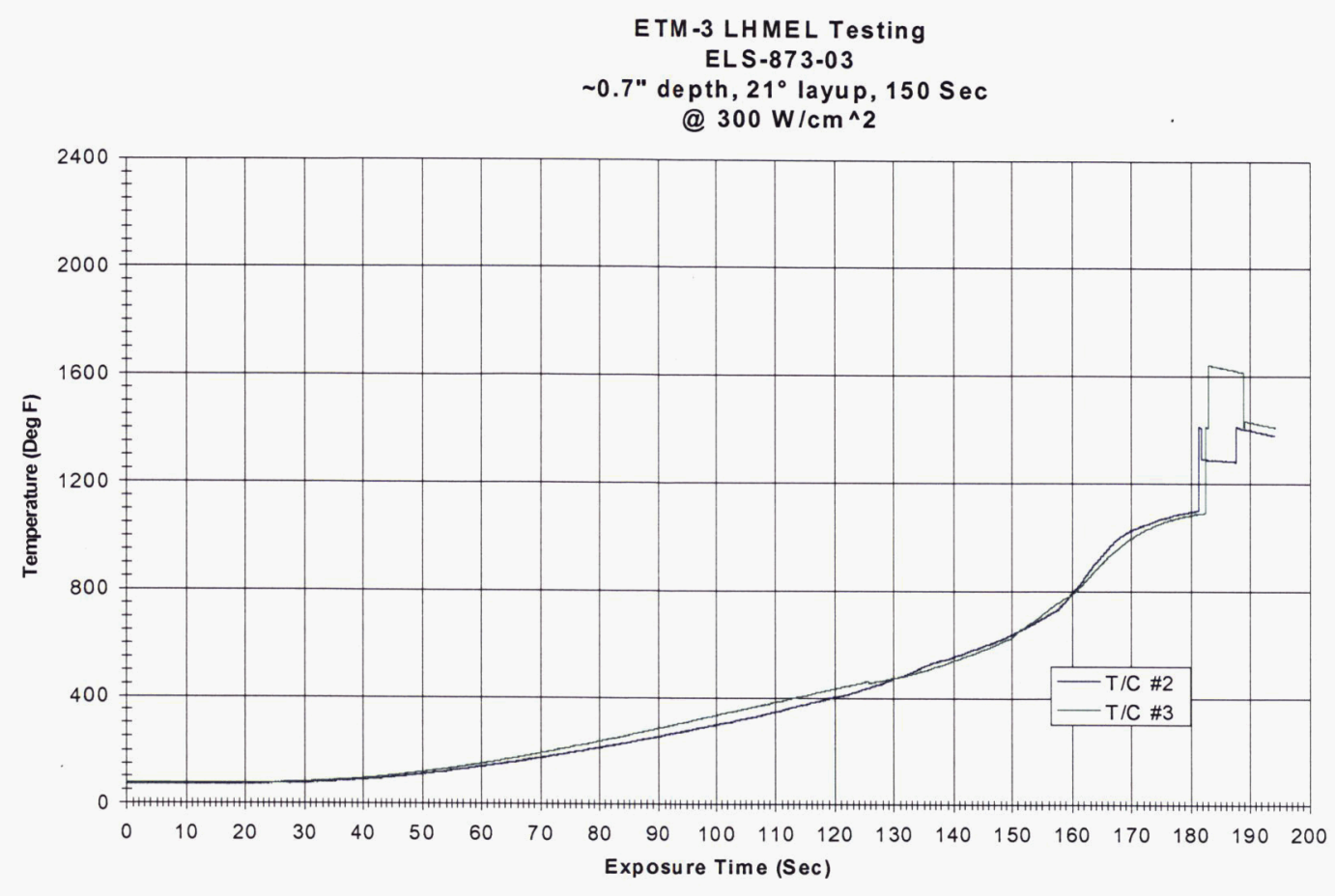

Figure 7: ELS-873-02 TC Plug LHMEL Test Results

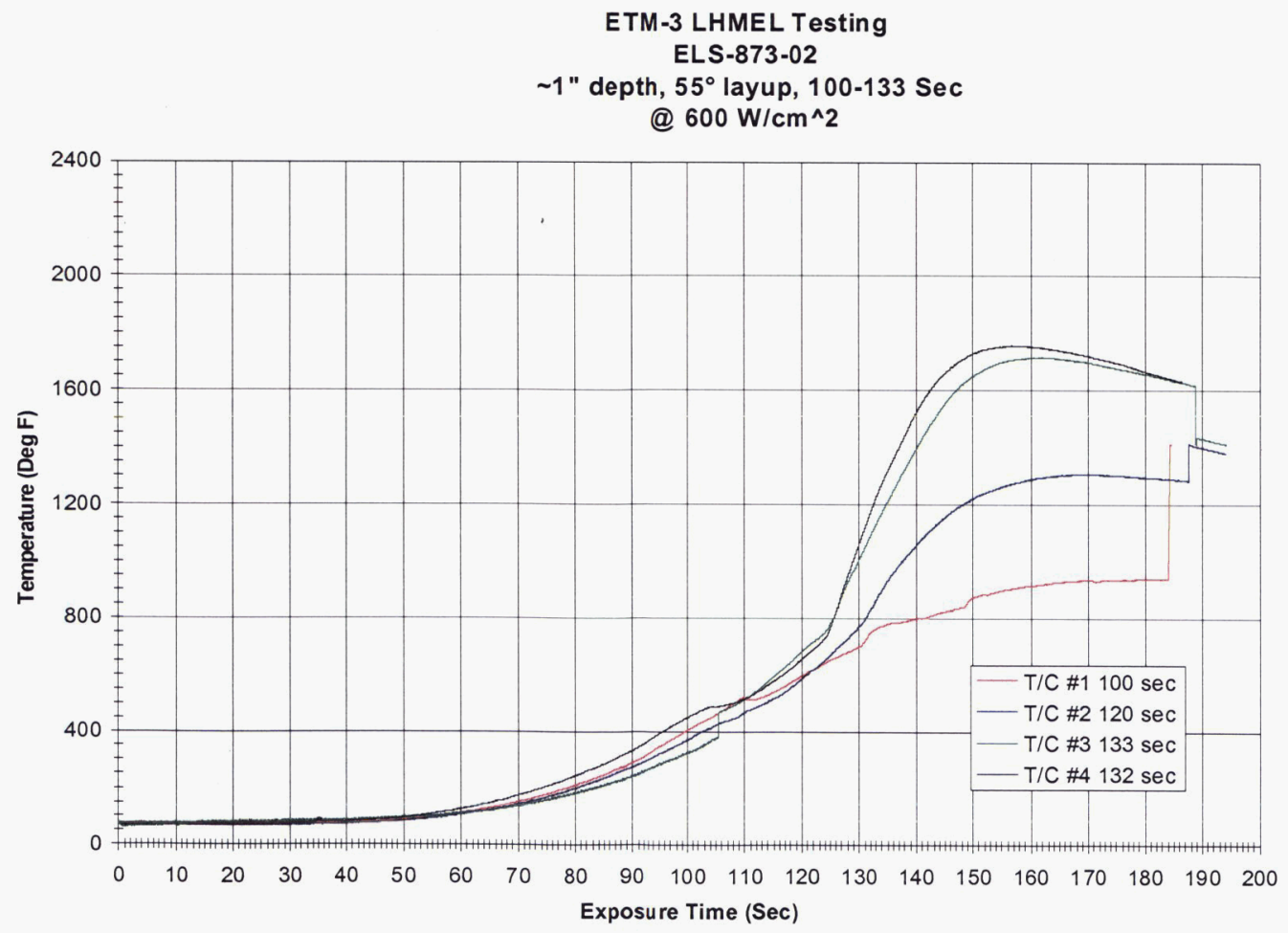

Figure 8. ELS-873-02 TC Plug LHMEL Test Results 

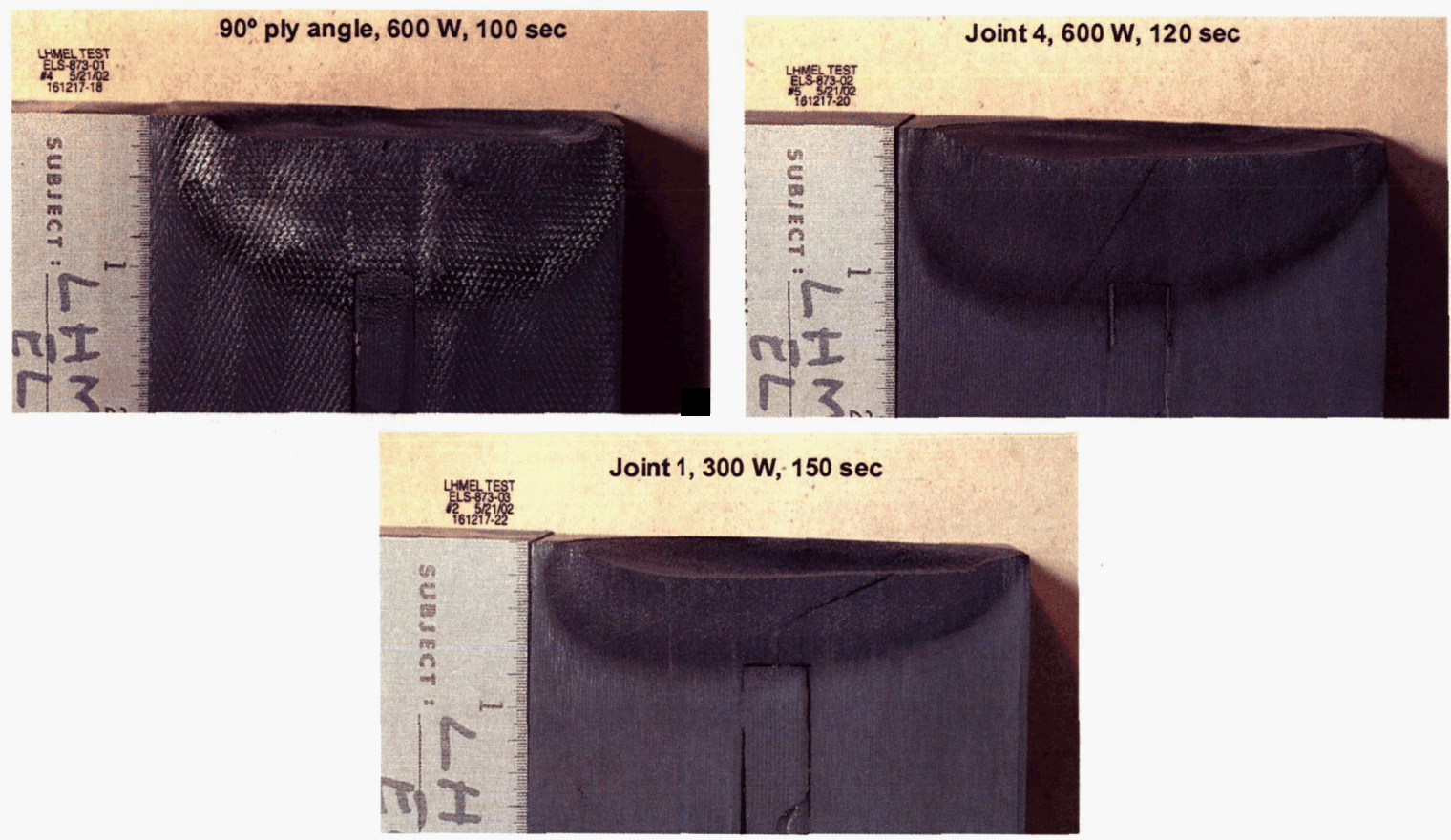

Figure 9: Nozzle Joint Simulation Tests

\section{B. Thermocouple Plug Verification}

The selected TC plug design was installed in a nozzle of the 24-inch SRTM Nozzle Verification (NV) test bed to provide verification for a) installation of instrumentation, b) pretest instrumentation check out, and c) acquisition of data during the motor firing. The test was conducted in the East Test Area at Marshall Space Flight Center. Figure 10 provides an overview illustration of the motor and lists the nominal parameters typical for the motor firing. The axial locations of the TC plugs are depicted in Fig. 11. The angular location and depth from the flame surface are summarized in Table 2.
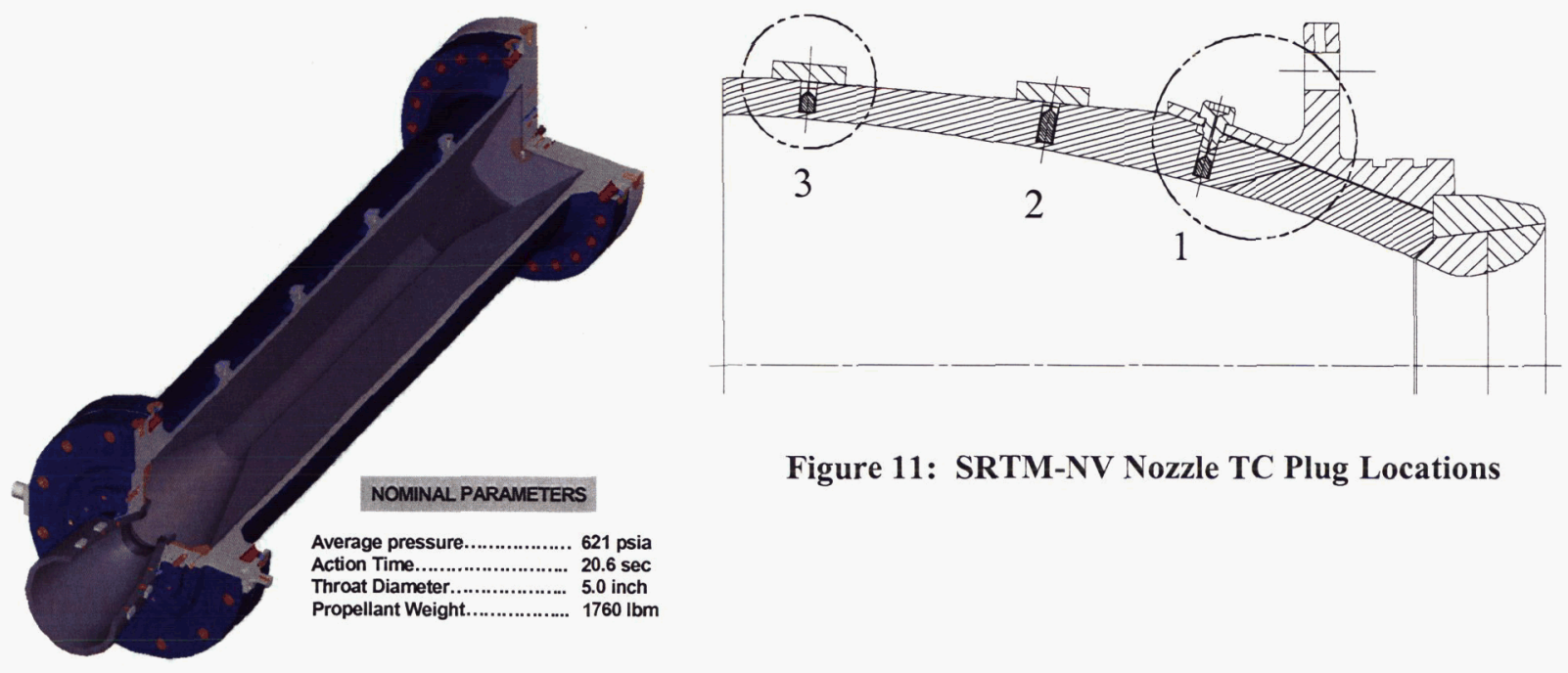

Figure 11: SRTM-NV Nozzle TC Plug Locations

Figure 10: SRTM-NV Test Motor 
Table 2: SRTM-NV Nozzle TC Plug Locations and Depths

\begin{tabular}{|c|c|c|c|c|}
\hline Axial Location & $\begin{array}{c}\text { Nozzle } \\
\text { Component }\end{array}$ & Temperature Gage & $\begin{array}{c}\text { Angular } \\
\text { Location (deg.) }\end{array}$ & $\begin{array}{c}\text { Depth From Flame } \\
\text { Surface (in.) }\end{array}$ \\
\hline 1 & Shear Pin & T001 & 0 & 0.177 \\
& & T002 & 90 & 0.177 \\
& & T003 & 180 & 0.177 \\
\hline 2 & TEC Phenolic & T004 & 0 & 0.177 \\
\hline & & T006 & 90 & 0.177 \\
& & T007 & 180 & 0.177 \\
& & T008 & 270 & 0.177 \\
& AEC Phenolic & T009 & 0 & 0.177 \\
\hline & & T010 & 90 & 0.177 \\
& & T011 & 180 & 0.277 \\
& & T012 & 270 & 0.177 \\
& & & & 0.277 \\
\hline
\end{tabular}

The TC plug design consisted of a 5-mil Type $\mathrm{K}$, Chromel-Alumel wire cured in a ceramic adhesive to provide both rapid response and high temperature $\left(2500^{\circ} \mathrm{F}\right)$ capability. Figure 12 provides a conceptual view of the TC plug. The plug (0.44-inch nominal diameter) was installed into a 0.47 -in.-diameter flat bottom hole, drilled from the outside, non-flame path, of the nozzle cone.

Holes were drilled at the desired depths as shown in Table 2. The desired depths were measured using coordinate measurement machine (CMM) techniques to record the material remaining between the bottom of the TC plug hole and the inside diameter (ID) of the nozzle. A total of 12 in-depth gages were installed. The four gages at each axial station were circumferentially spaced 90 degrees apart.

The ply orientations of the plugs were aligned with the phenolic liner ply angles to better match the thermal conductivity. A 2 × 2-in. aluminum mounting block, designed as a redundant gas path seal, was bonded to the outside diameter (OD) side of the plug. This instrumentation installation technique is illustrated in Fig. 13. TC plugs installed under shear pins did not require the installation of aluminum blocks. An electrical continuity and resistance checkout was conducted to monitor contact between the TC junction and the nozzle liner during and after installation to demonstrate gage functionality. The instrumentation and installation techniques used during this technology demonstration were a precursor to those used in the ETM-3 nozzle.
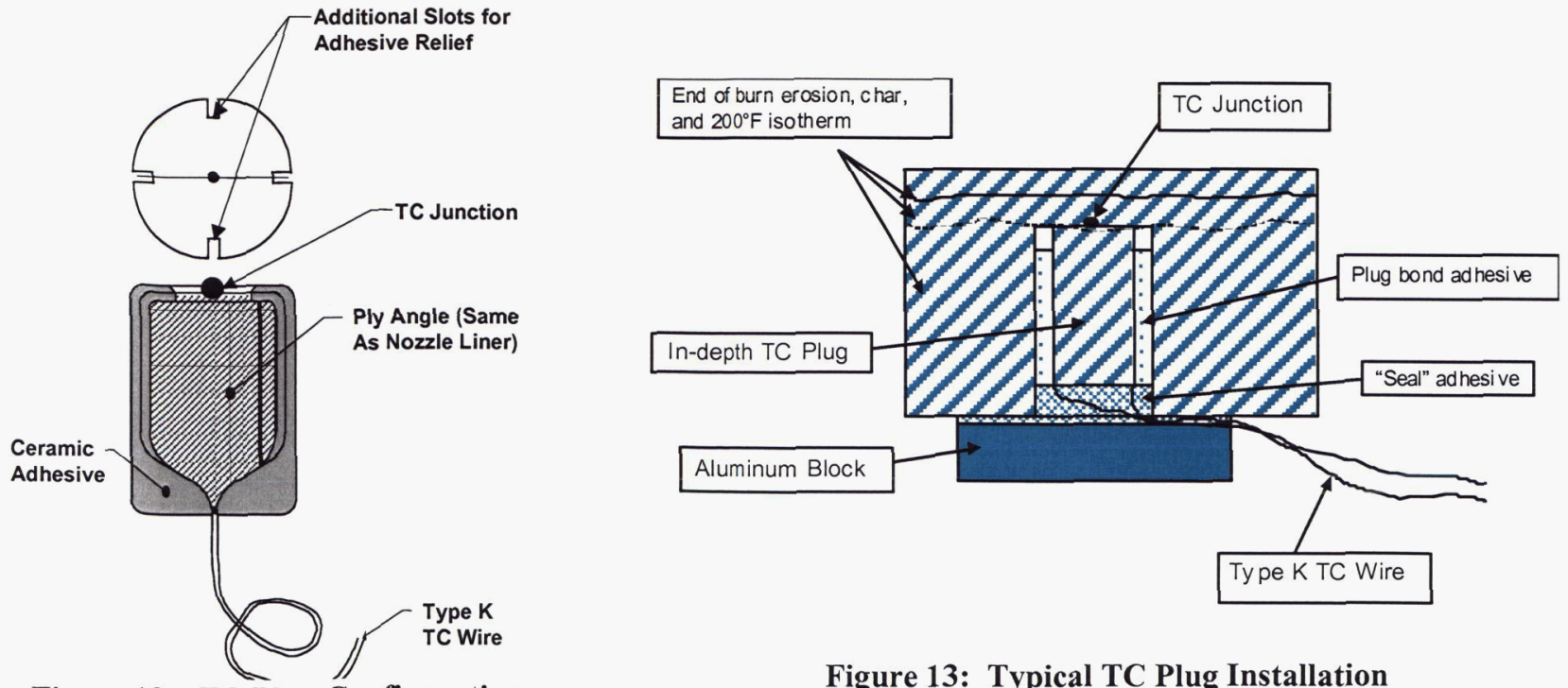

Figure 12: TC Plug Configuration

Figure 13: Typical TC Plug Installation 
Table 3: Thermocouple Plug Placement in ETM-3 Nozzle

\begin{tabular}{|c|c|c|c|c|c|c|}
\hline Station & $\begin{array}{c}\text { Approximate Distance } \\
\text { From Throat Axial Station } \\
\text { Measured to CCP/GCP } \\
\text { Interface (in.) }\end{array}$ & $\begin{array}{c}\text { Nozzle } \\
\text { Component }\end{array}$ & $\begin{array}{c}\text { Temperature } \\
\text { Gage }\end{array}$ & $\begin{array}{l}\text { Angular } \\
\text { Location }\end{array}$ & $\begin{array}{l}\text { Proposed } \\
\text { Depth From Flame } \\
\text { Surface (in.) }\end{array}$ & $\begin{array}{l}\text { Articulated Arm CCM } \\
\text { Measured Depth From } \\
\text { Flame Surface (in.) }\end{array}$ \\
\hline \multirow{4}{*}{21} & \multirow{4}{*}{123.9} & \multirow{4}{*}{ AEC Phenolic } & T001 & 21 & 0.70 & 0.685 \\
\hline & & & T002 & 111 & 0.60 & 0.531 \\
\hline & & & T003 & 201 & 0.70 & 0.692 \\
\hline & & & T004 & 291 & 0.60 & 0.587 \\
\hline \multirow[t]{4}{*}{22} & \multirow[t]{4}{*}{154.2} & \multirow[t]{4}{*}{ AEC Phenolic } & T005 & 21 & 0.72 & 0.718 \\
\hline & & & T006 & 111 & 0.62 & 0.549 \\
\hline & & & T007 & 201 & 0.72 & 0.691 \\
\hline & & & T008 & 291 & 0.62 & 0.585 \\
\hline
\end{tabular}

The TCs were placed at a depth such that they would reach $1000^{\circ} \mathrm{F}$ (CCP char depth) or greater by the end of the test. All of the TCs at stations 1 and 2 were placed at 0.177 inch. At station 3, the TCs at 0 and 180 degrees were at 0.177 inch, whereas those at 90 and 270 degrees were placed at 0.277 inch.

The TC data from the test are presented in Figures 14 through 16, for stations 1 through 3, respectively. Each one of the charts also includes the predicted temperature history at the TC depths for comparison. At station 1, only the TCs at 0 and 270 degrees functioned properly. At station 2, all four TCs functioned properly. At station 3, TCs at 0 , 180 , and 270 degrees were operational. All of the functional TCs reached $1000^{\circ} \mathrm{F}$ before the end of motor operation.

The TC results at stations 1 and 2 matched best to the predicted temperature histories at those locations. The predicted temperature history starts higher than the measured temperature data, but ends up slightly lower. This is somewhat typical of the current thermal model for CCP for in-depth temperature response. The TC results from station 3 are quite a bit higher than the predictions. This is likely due to an under prediction of the erosion. The nozzle was built to enhance particle impingement in the AEC. Based on preliminary examination of the postfired hardware, the augmented erosion due to particle impingement was underestimated. At station 3 , the erosion actually reached the TC plugs at the 0 - and 180 -degree locations where the TCs were at a depth of 0.177 inch.

C.

TC Plugs Station 1

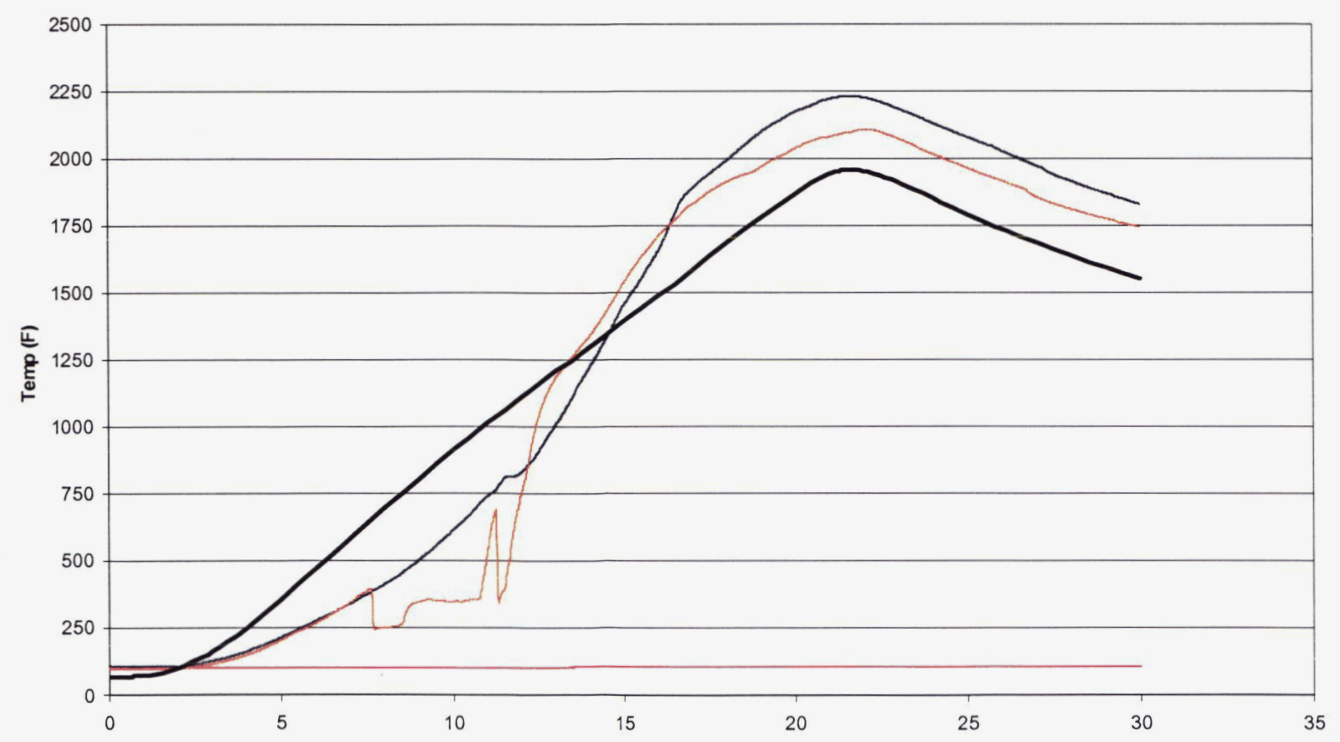

Figure 14: $\quad$ SRTM-NV Temperatures at Station 1 


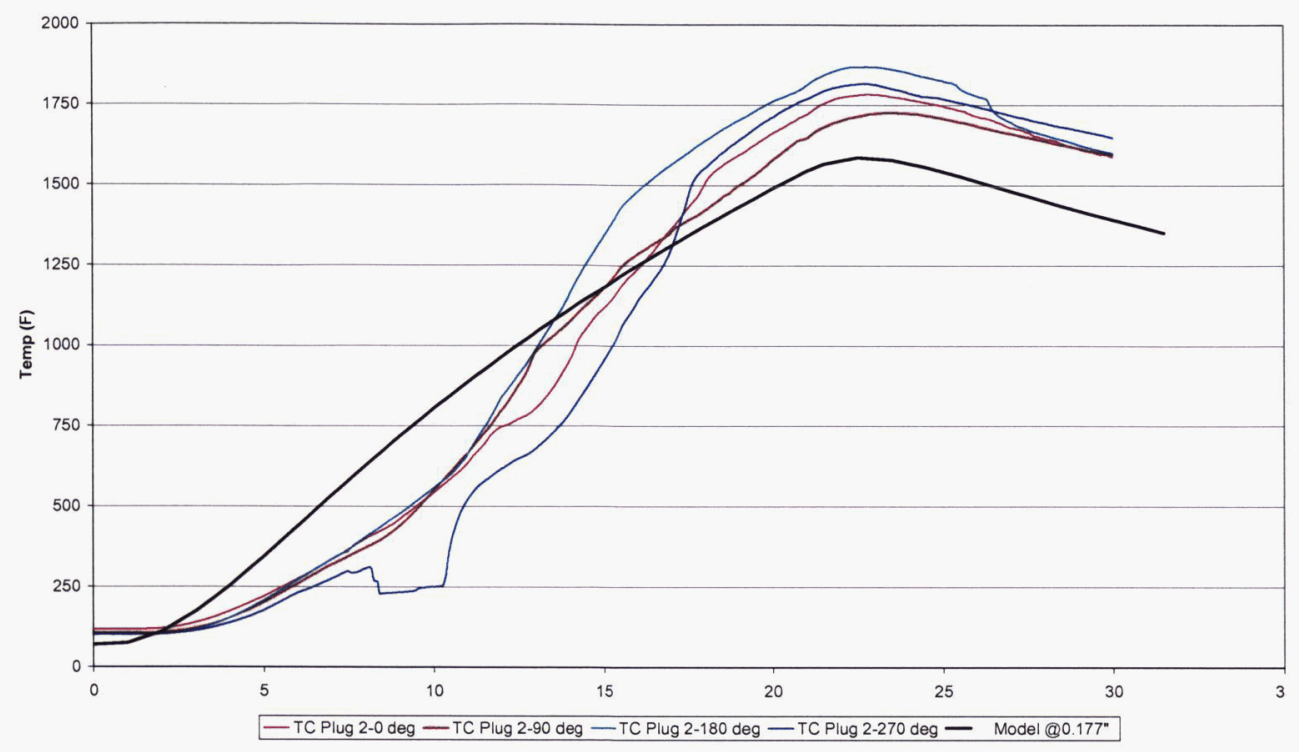

Figure 15: SRTM-NV Temperatures at Station 2

TC Plugs, Station 3

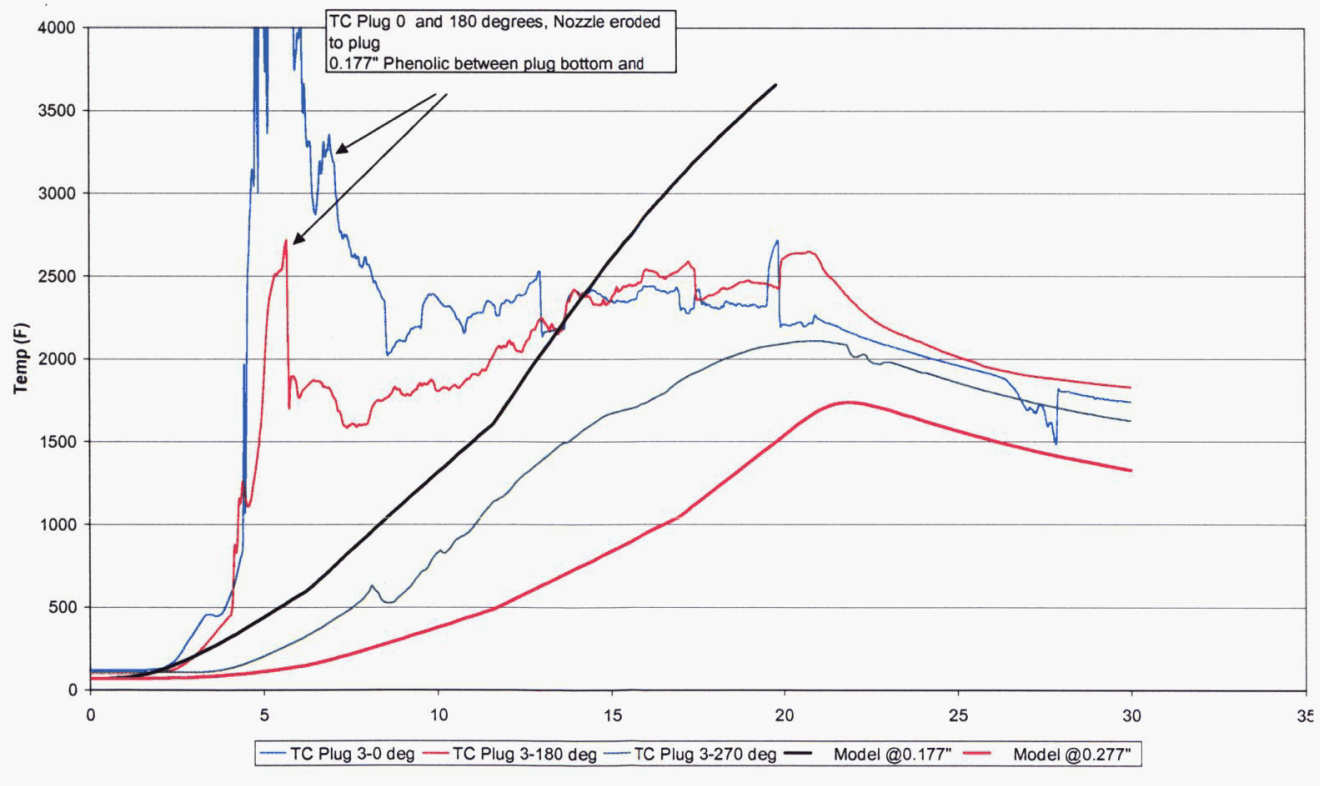

Figure 16: SRTM-NV Temperatures at Station 3

\section{ETM-3 Nozzle Thermocouple Plug Implementation}

Again, one of the goals of the ETM-3 test was to verify thermal models using instrumentation that provides realtime transient temperature response. The development and verification of in-depth TC plugs at LHMEL and on the SRTM-NV allowed that goal to come to fruition. The process of installing the TC plugs in the ETM-3 AEC was carefully conducted to ensure accurate measurement of in-depth temperature during the hot-fire testing. The first step was to drill holes to the desired depths per the assembly drawing. Holes were drilled from the OD-side using the Bridgeport computer-numerical-controlled machine to precisely locate the plugs. Measurements of the remaining liner thickness between the bottom of the holes and the flame-side surface were taken by two different methods. 
First, a mechanical measurement was made using a portable articulated arm CMM and then verified with a depth micrometer. The axial orientation (fore and aft) was marked on the base of the plug to ensure ply angle lineup. The plugs were then dry fit and the outboard clearance (end of plug to OD liner) was checked. The plugs were removed and a bead of EA934NA adhesive was applied around the sides of the plug (adhesive is not applied to hot portion of plug OD perimeter). The TC plugs were next bonded into the holes such that the correct ply angle orientation was maintained. EA934NA was used to fill up gap clearance. TIGA-321 adhesive was injected into remaining hole depth (free volume in hole between outboard end of bonded plug and liner OD). Aluminum blocks were then bonded over the TC plugs. The final configuration is shown in Figure 17.

Initially, it was proposed that six axial stations in the FEC and AEC would house TC plugs. However, after risk evaluations were completed, it was concluded that TC plugs would only be installed at two axial stations near the end of the nozzle AEC. Those two stations are referred to as station 21 and station 22, which were the thermal station numbers assigned for the ETM-3 thermal analysis. Four TC plugs were spaced 90 degrees around the circumference of the nozzle at each station for a total of eight TC plugs. Figure 18 shows a cross-sectional view of the AEC with the TC plug locations defined. Table 3 summarizes the locations of the TC plugs on the AEC, the proposed TC depths, and actual depths as measured by the articulated arm CMM. Three-dimensional crosssectional views of the ETM-3 plug configurations are shown in Figure 19. The TCs were used to gather the temperature data during and after motor operation. Two of the TC plugs at each axial station were placed at depths that were at the RSRM nominal measured char depth (corrected to end of burn) in order to portray the carbon phenolic temperature response during the charring process. The other two TC plugs at each

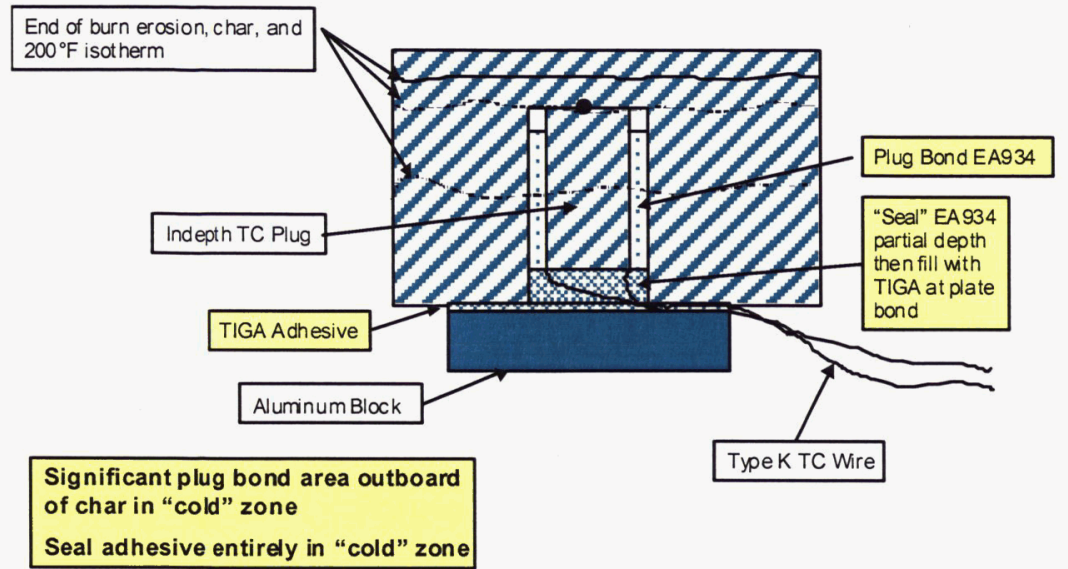

Figure 17: ETM-3 Plug Installation Process

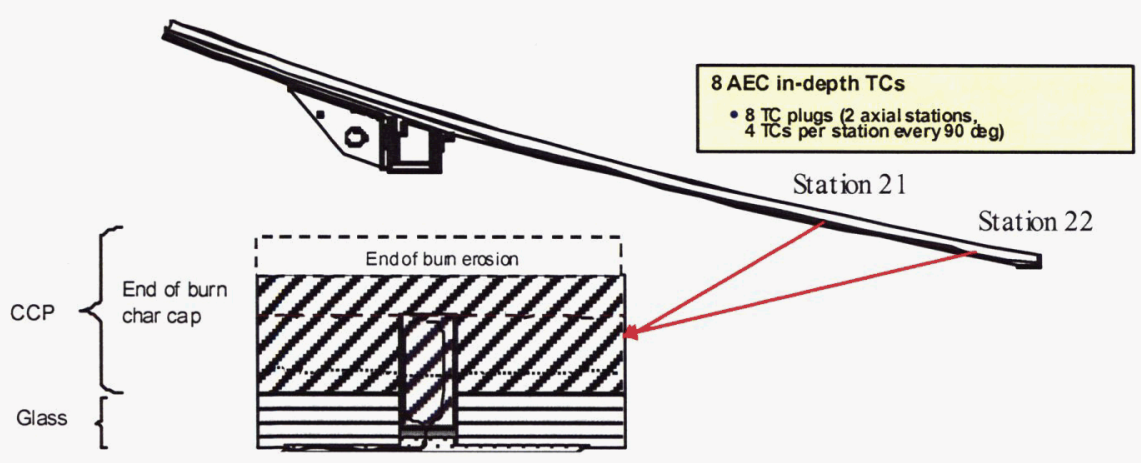

Figure 18: ETM-3 Thermocouple Plug Locations
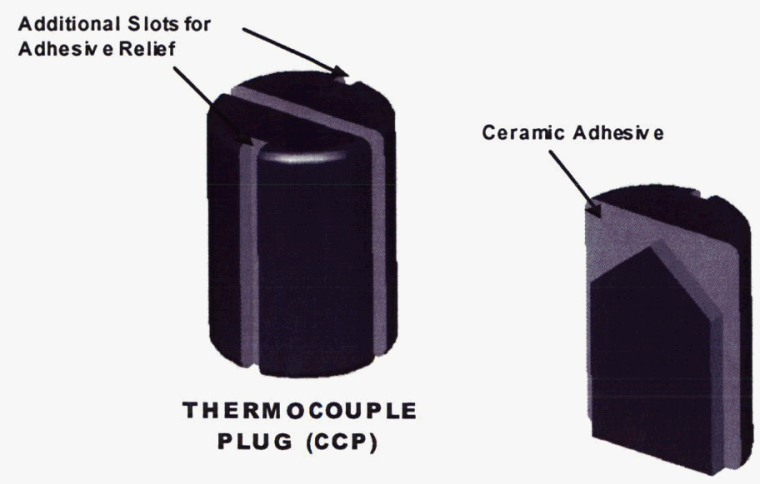

CUTAWAY VIEW

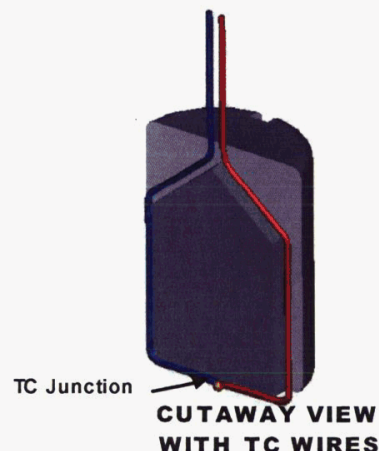

Figure 19: ETM-3 Thermocouple Plug Configuration 
station were placed at the char depth +0.1 inch to capture the temperature gradient during temperature rise and resulting in-depth charring. The TC depths were determined based on nominal RSRM erosion calculations rather than maximum erosion so that the char progression would more likely be captured. Figures 20 and 21 show the TC plug placement at stations 21 and 22 , in relation to the predicted temp-erature gradients at the end of burn. The gradients for nominal RSRM erosion and maximum ETM-3 erosion are shown as bounding cases.

\section{Post-test Evaluation}

The ETM-3 motor was successfully test fired on 23 October 2003 at the T-97 large motor static test bay at ATK Thiokol's Promon-tory, Utah, test facility. Preliminary evaluation of the instrumentation data indicated that all eight TCs functioned properly and yielded valid tempera-tures (T002 was lost at $\sim 60 \mathrm{~s}$ after end of burn). The TC temperature data were similar to prefire predictions that assumed nominal erosion. Figures 22 and 23 show the temperature histories measured by the TC plugs for thermal stations 21 and 22 , respectively. The measurements were recorded during motor operation through the end of burn and for approximately three minutes following end of burn.

The AEC was dissected in order to measure the erosion and char at the locations of the TC plugs. Figure 24 shows a cross section of one of the T005 TC plugs and the surrounding material after it was dissected. In all cases the char line was at or near the depth of the TC at the top of the plugs, which was one of the main objectives. Thermal models for each of the TC locations were updated such that the measured erosion was matched. This was accomplished by adjusting the heat transfer coefficients until the erosion calculated by the thermochemical model matched the measured erosion for each station. Figures 25 and 26 show comparisons between the measured TC temperatures and the model calculated temperatures again for thermal stations 21 and 22 , respectively. Based on the in-depth temperature measurements, the current analytical model for CCP predicts the temperature response fairly well. The model is slightly conservative compared to the actual data as the material is initially heated. However, both predicted and measured reach peak temperatures about the same time. Based on the measured TC data, the thermal models have been successfully verified. 


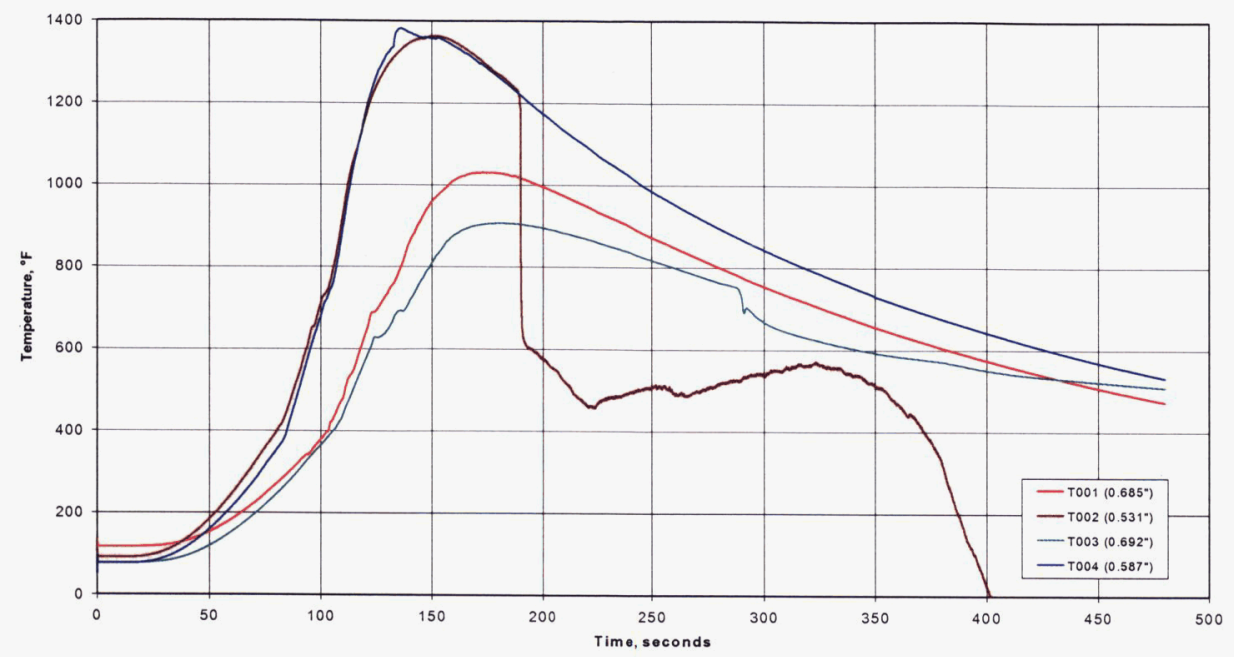

Figure 22 ETM-3 In-depth Thermocouple Temperatures at Station 21.

III.

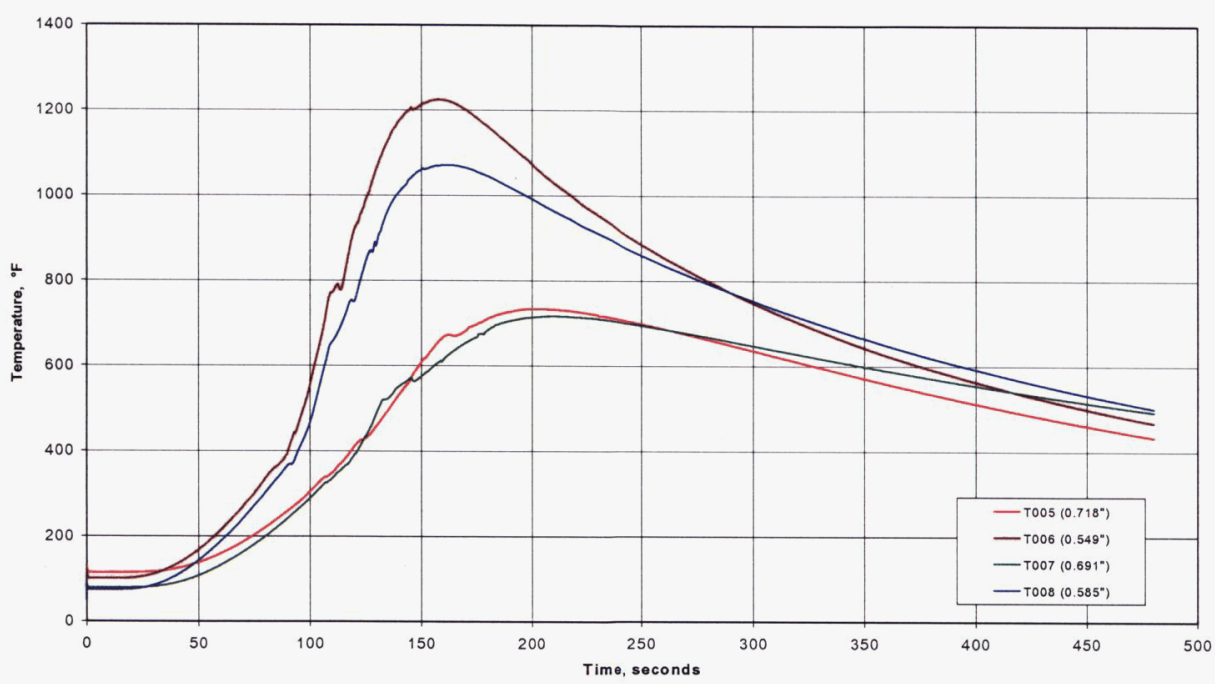

Figure 23 ETM-3 In-depth Thermocouple Temperatures at Station 22.

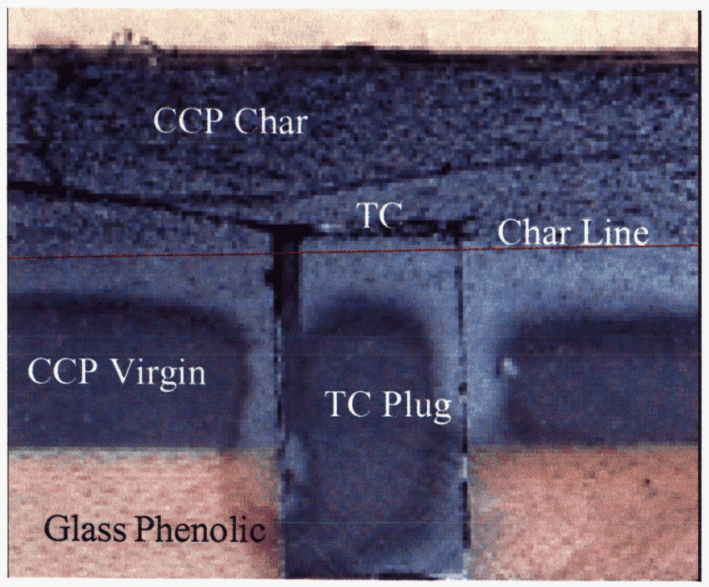

Figure 24 Cross Section of Dissected TC 


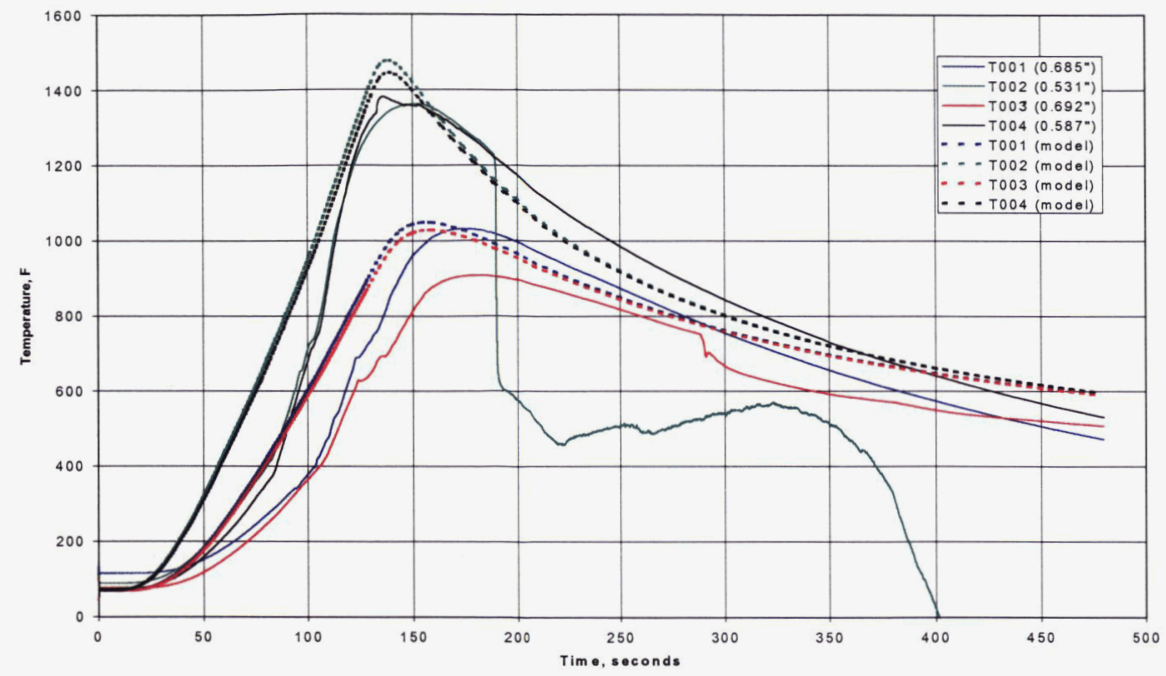

Figure 25 Thermal Station 21 Temperature Comparisons.

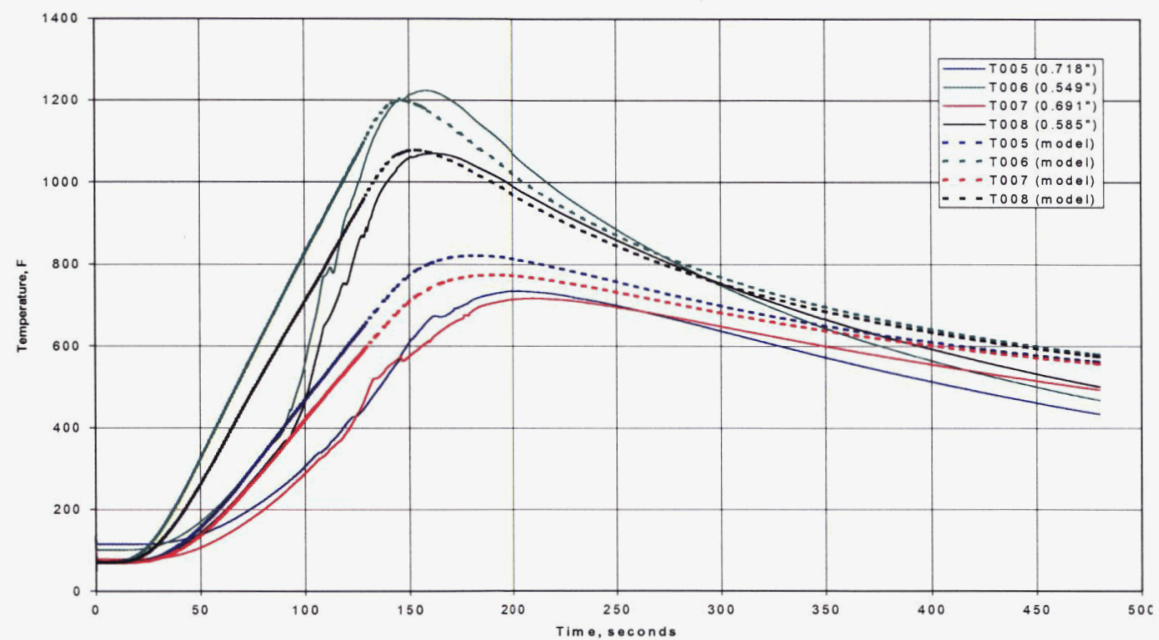

Figure 26 Thermal Station 22 Temperature Comparisons.

\section{Conclusions}

With the implementation of TC plugs in the ETM-3 nozzle AEC, the goal to verify thermal models with realtime transient temperature response in the ablating phenolic liner was achieved. The Transducer Development organization at ATK Thiokol successfully developed a TC plug design that replicates the "ideal case" design, which consists of cured-in-place TCs. The in-depth TC plug technology has again been successfully applied to an AEC on a large scale. Post-test inspection of hardware and evaluation of instrumentation data indicated that the test was successful and the results were acceptable. No gas path leakage was observed with the new developed process. The test objectives were achieved and the TC plug design and installation techniques demonstrated minimal hardware risk.

Presently, there is no plan to adjust the baseline CCP model based on the ETM-3 TC data. It is recommended that technology developed for the ETM-3 AEC program, be applied to other RSRM AECs so that additional data can be gathered. Further testing is required to justify changes to the CCP thermal model. 


\section{Acknowledgments}

The concept of measuring in-depth temperatures in nozzle ablative liners of large-scale motors is relatively new. The idea of drilling holes for the purpose of placing TC plugs is an RSRM nozzle would not have been considered a few years ago. There has been a great amount of effort to convince the community that the TC plug design concept presents minimal hardware risk. Many professionals have provided input to the development of the TC plug design, the verification methods used to ensure the optimal design, and placement for use in the ETM-3 AEC. The authors thank all personnel of Test Operations, the Test Transducer Development Lab, the Nozzle Work Center, Nozzle Design, Manufacturing Engineering, Heat Transfer, and Science and Engineering Huntsville Office. Special thanks goes to many of the professionals working in these departments including, but not limited to, Fred Perkins, Lon Hyer, Buddy Buttars, Larry Wilkes, Lloyd Johnson, Bruce Loftus, Dave Day, Dave Detwiler, Fred Jones, Mike Cornelius and Ounyoung Park.

\section{References}

${ }^{1}$ Maw, J. F., "ETM-3 Nozzle Heat Transfer and Erosion Analysis," ATK Thiokol, TWR-74423, Rev. A, 19 July 2002.

${ }^{2}$ Maw, J. F., "Aero/Thermal Analysis of the RSRM Nozzle," ATK Thiokol, TWR-17219, Rev. E, 17 April 2002.

${ }^{3}$ Ahmad, R., and Morstadt, R., "RSRM and ETM03 Internal Flow Simulations and Comparisons," ATK Thiokol, TWR-74422, February 2002.

${ }^{4}$ Tobias, M., "ETM-3 Ballistics Analysis," ATK Thiokol, TWR-74409, February 2002.

${ }^{5}$ Buttars, R. L., "Material Thermal Properties Database Reference Report," ATK Thiokol, TWR-66518, Rev. D, 25 June 2002.

${ }^{6}$ Lui, R. C., "RSRM Nozzle In-depth Thermocouple Plug Testing," ATK Thiokol, ETP-1992, January 2002.

${ }^{7}$ Lui, R. C., "Evaluation of Thermocouple Plug Performance," ATK Thiokol, TWR-74530, 26 September 2002. 